\title{
Evaluating a Student MIS in the Tertiary Education Sector: Addressing Functional-Operational Misalignment through Continuous Participative Evaluation
}

\author{
Marian Carcary \\ Kemmy Business School, University of Limerick, Limerick, Ireland. \\ Email: marian.carcary@ul.ie
}

Received September $16^{\text {th }}, 2009$; revised November $2^{\text {nd }}, 2009$; accepted December $7^{\text {th }}, 2009$.

\begin{abstract}
The Information and Communications Technology (ICT) evaluation literature spans several decades. ICT evaluation approaches range from objective and positivistic to subjective and interpretive. While positivistic approaches have dominated the past, there is increasing recognition of the value of interpretivist methods and the need for ongoing project evaluation. Formative continuous participative evaluation (CPE) offers several benefits in terms of project control, enhanced stakeholder relationships and benefit realisation; nonetheless this is often ignored in practice. There is a paucity of ICT evaluation within the Higher Education sector. The 14 Irish Institutes of Technology (IoTs) recently underwent an extensive transformation of their ICT systems, through a nationwide implementation of a suite of integrated IS. This research study, centred on the evaluation of the Student MIS implementation was interpretive in nature; case studies were conducted in five IoTs. This paper focuses specifically on one issue uncovered through the research i.e. the misalignment between the Student MIS and the IoTs requirements. The paper proposes a set of guidelines for addressing this issue through focusing on the theoretical underpinnings of CPE and its importance for organisational learning and benefit realisation.
\end{abstract}

Keywords: ICT Investment Management, ICT Evaluation, Formative Evaluation, Continuous Participative Evaluation, MIS, ICT in Tertiary Education

\section{Introduction}

ICT evaluation research has attracted the interests of academics and practitioners for several decades. Evaluation approaches can be viewed along a spectrum that ranges from objective, rational, positivist approaches to subjective, interpretive approaches [1]. The former have historically dominated ICT evaluation research [2], at the expense of contextual issues. However, in recent years, interpretive approaches have gained a stronger foothold. There is growing consensus that evaluation needs to be formative in nature i.e. ongoing throughout the project lifecycle [3-6]. Gemmell and Pagano (2003) [7] suggest that organisations would benefit from moving towards a continuous evaluation approach that was integrated into the project management process. Arguments for continuous evaluation include project control, adaptability, Value realization and improved relationships [8]. The formative approach seeks to explore all project issues, identify unexpected impacts, assess the degree to which the project proceeds as planned and provide feedback to improve project performance. It focuses on complex interactions between people and technology, and considers the system's short-term and intermediate effects and its influence on stakeholders.

Many authors have argued that ICT evaluation needs to be dynamic and continuous across the project lifecycle (see for example [9-13]). This is necessary in order for what Willcocks (1992) [14] terms the "islands of evaluation" to become integrated and for continuous improvement opportunities to be identified. A particular type of formative evaluation is Continuous Participative Evaluation (CPE). Continuous participative approaches for example Remenyi et al's (1997) [15] Active Benefit Realisation $\left(\mathrm{ABR}^{1}\right)$, promote stakeholder involvement, motivation and commitment and improve ICT decision-making 
through establishing dialogue with all affected parties. Cordoba's (2009) [16] development of a methodological framework to support the process of IS planning emphasises continuous identification of concerns from stakeholders; it promotes continuous dialogue, listening and mutual collaboration between participants and facilitates critical reflection in the exploration of possibilities for improvement. CPE is integrated into organisational daily activities with a continuous focus on stakeholders, ICT quality and evolving business objectives. Stakeholder participation helps improve functionality, helps identify and manage intangible impacts, stimulates organisational learning, focuses attention on issues that impair ICT success, helps maximise ICT benefit realisation and reduces the culture gap between business and ICT domains. Throughout the 1980s and 1990s the concept of an "evaluation party" [17] emerged to emphasise the importance of stakeholder views.

Despite its usefulness, formative continuous participative evaluation is often not conducted in practice. Willcocks et al. (1999) [18] suggested that few companies evaluate strategic, business, end-user and technical performance in an integrated manner throughout the system's lifecycle. Evaluation declines following project feasibility assessment; it is poorly linked across lifecycle stages; and little learning for future ICT investments is derived. Further, Hillam and Edwards (2001) [19] stated that user perception is rarely considered. Lack of involvement can result in decreased commitment or negative attitudes. For example, Markus (2004) [20] claimed that approximately $75 \%$ of organisational change efforts driven by technology fail because of negative stakeholder reactions to work practice, business process and technology changes.

This paper discusses the need for formative continuous participative evaluation mechanisms in addressing some of the problems resultant from a large-scale standard Student MIS implementation in the Irish Institutes of Technology (IoTs). To date, there is a paucity of evaluation research in the tertiary education sector [21]. Further research is required in this area as the ICT systems that support student administrative operations represent the means for competitive parity with or advantage over other educational establishments. This paper discusses

\footnotetext{
${ }^{1} \mathrm{ABR}$ shifts the focus away from technical issues towards stakeholder involvement. Each stakeholder level plays a co-creation and coevolutionary role in systems development and in achieving results, and is responsible for ICT management. In the process, the primary issues and evaluation information are summarised in documents called pictures-a business picture and a supporting financial picture and project picture. Evaluation consists of three phases-setting the course, formative evaluation, and moving forward after feedback; and seven key activities-initialisation, production of pictures, agreement to proceed, systems development, evidence collection, participative evaluation and development of updated pictures. This evaluation process continues in an iterative manner.
}

one of the key findings that were distilled from the Student MIS evaluation processes undertaken - the issue of functional-operational misalignment. It proposes a set of guidelines to help the IoT sector address this issue through focusing on the importance of formative CPE approaches. The evidence suggests that the approaches adopted in the implementation and operationalisation of the Student MIS did not emphasise the importance of evaluation exercises; however, this paper suggests that future benefit potential realisation can be enhanced through adopting formative CPE methods.

\section{The MIS Project in the IoT Sector}

A proposal to investigate a collaborative acquisition of a MIS for the Irish IoT sector was initially raised in 1991/1992. This system sought to support new modes of education delivery, support IoT administrative operations, improve services to all stakeholders, streamline workflow and improve organisational communications and competitiveness. The project involved representatives from the Department of Education and Science (DoES) and the Council of Directors of the Irish IoTs. The system was selected by a team of 12 representatives from 8 IoTs. However, the mechanism used in tender evaluation was not sufficiently in-depth or not applied with the necessary rigour; hence it was felt by many stakeholders that the system selection decision was a misguided one. The initiative resulted in the implementation of a suite of integrated Information Systems (IS) for library, human resources, finance and student management functions in 15 Institutions. These systems were rolled out to the IoT sector in a series of implementation waves between 2000 and 2006. This paper focuses primarily on the impact of the Student MIS.

In an attempt to maintain a common national standard system design, a central project team was responsible for all system development. Any required system changes were managed through a central system change request process. Hence, the majority of IoTs did not have system development autonomy. While the central team offered the benefits of resource efficiency, development of specialisations, access to scarce resources etc, it was felt that the change request process to the central project team for expost system development was unnecessarily bureaucratic. Changes refused by the central team, on the basis that they were not required by the majority of IoTs, resulted in some sites using functionality they found to be unsuitable. Because any tailoring was designed to meet common requirements, the changes made were often compromises on specific needs. The bureaucracy of system change requests resulted in IoTs deviating from the common system standard through in-house developments that were adhoc and nonstandard across the sector. 
Commissioning of the Student MIS across the various implementation waves resulted in considerable work for both the central team and individual IoTs. There was a perceived lack of preparation for system commissioning which gave rise to negative stakeholder perceptions and detracted from staff willingness to embrace the system. System operationalisation resulted in multiple problems; these were linked to the system's complexities, lack of system configuration, lack of IoT preparation, and loss of IoT control to the central structure. Further, in many IoTs, the project teams established for system implementation were disbanded/scaled back too early, hence there were little resources to support problems or exploit system capabilities. However, following a period of system use, staff's increased familiarity with the system led to the realisation of a not insignificant flow of benefits. Benefits included for example improved structure, data standards and data access; job and management related benefits; improved quality procedures; and staff empowerment; and the Student MIS also served as a platform for future IoT ICT developments.

\section{The Student MIS Explained}

This Student MIS was oriented towards the US market and was anticipated to cater for all stages of a student's interaction with an IoT. The system had comprehensive functionality for course and subject management, student data, admissions application processing, student registration, maintenance grants payments, accounts receivable and fees assessment, examinations and academic history, student progression and graduation. Details of its modules are discussed in Table 1:
Figure 1 provides an overview of how these Student MIS modules were integrated. Firstly, biodemographic data is captured to facilitate admissions applications processing. These applications may come from the CAO or be made directly to the IoT. The applications are verified against the catalogue of existing courses. Following acceptance of a course place, the individual's data is used to create a student record. All students are registered at the individual subject level; this is made possible by the breakdown of subjects into their respective delivery modes based on the ACS. This registration is required for student fee assessment, maintenance grants payments and for examination results processing. All results are transferred to an academic history archive; they become the basis for student graduation from a completed programme or progression to the following academic year, where a new student record is created.

\section{Research Methodology}

The research methodology used in evaluating the impact of the Student MIS was interpretive in nature. The interpretive paradigm offered the opportunity to develop an in-depth understanding of the ICT system's impact; it facilitated the capture of contextual depth and detailed, nuanced descriptions; and avoided the unproblematic, value-free view of organisations associated with positivist approaches. The study's research methodology is outlined in Figure 2. The case study was the selected research method and was based on data collected from five sources-organisational websites, project documentation, newspaper articles, independent reports and semi-structured interviews.

\section{Table 1. Student MIS modules}

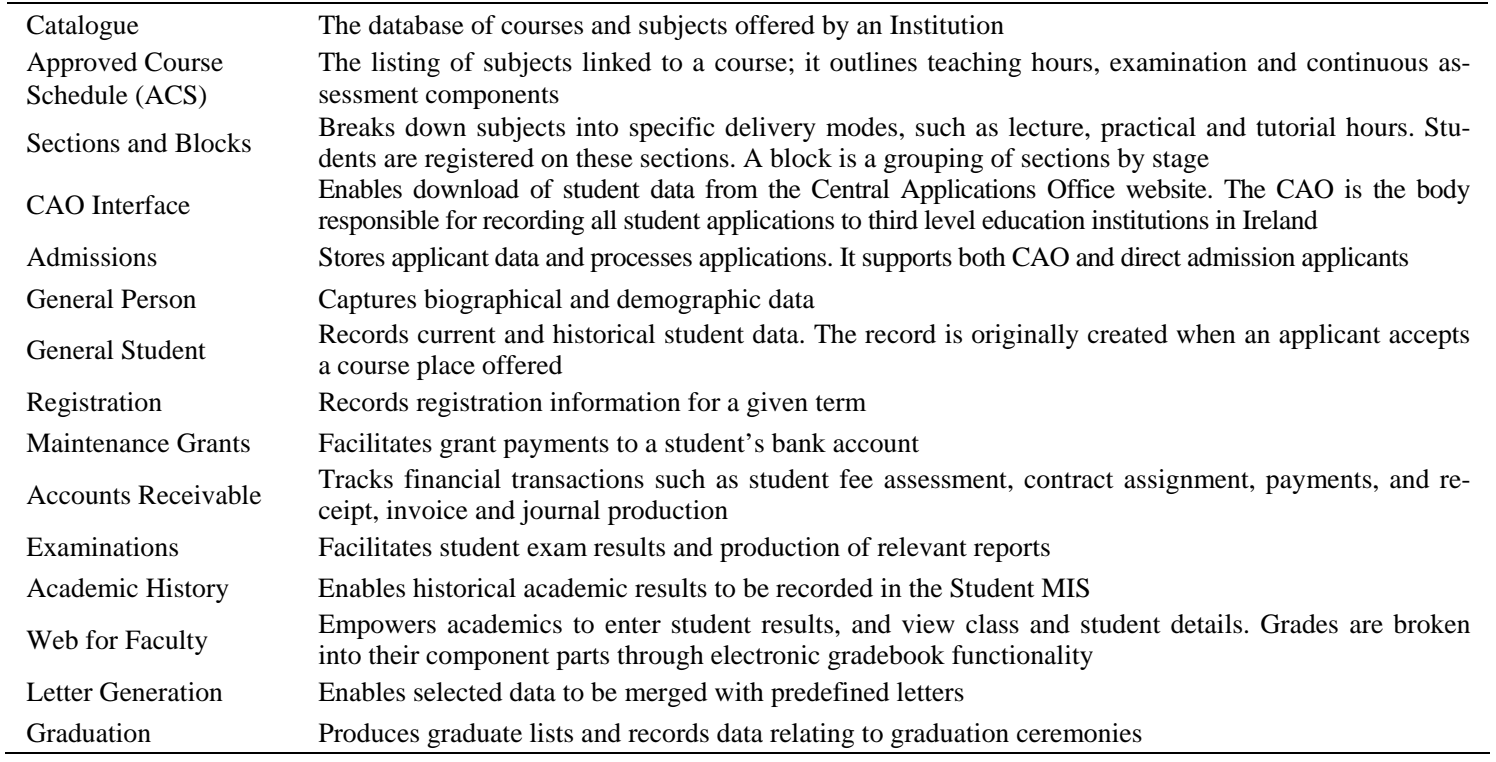




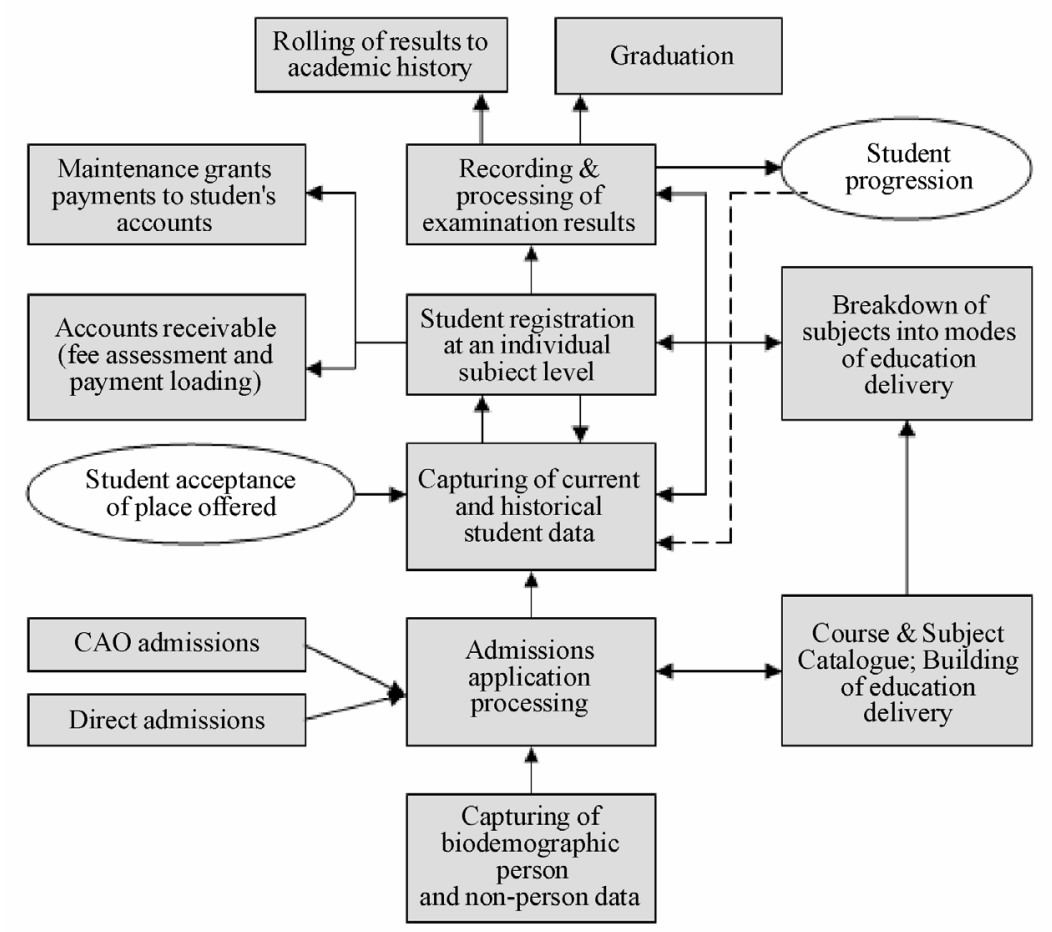

Figure 1. Functionality and operations of the student MIS

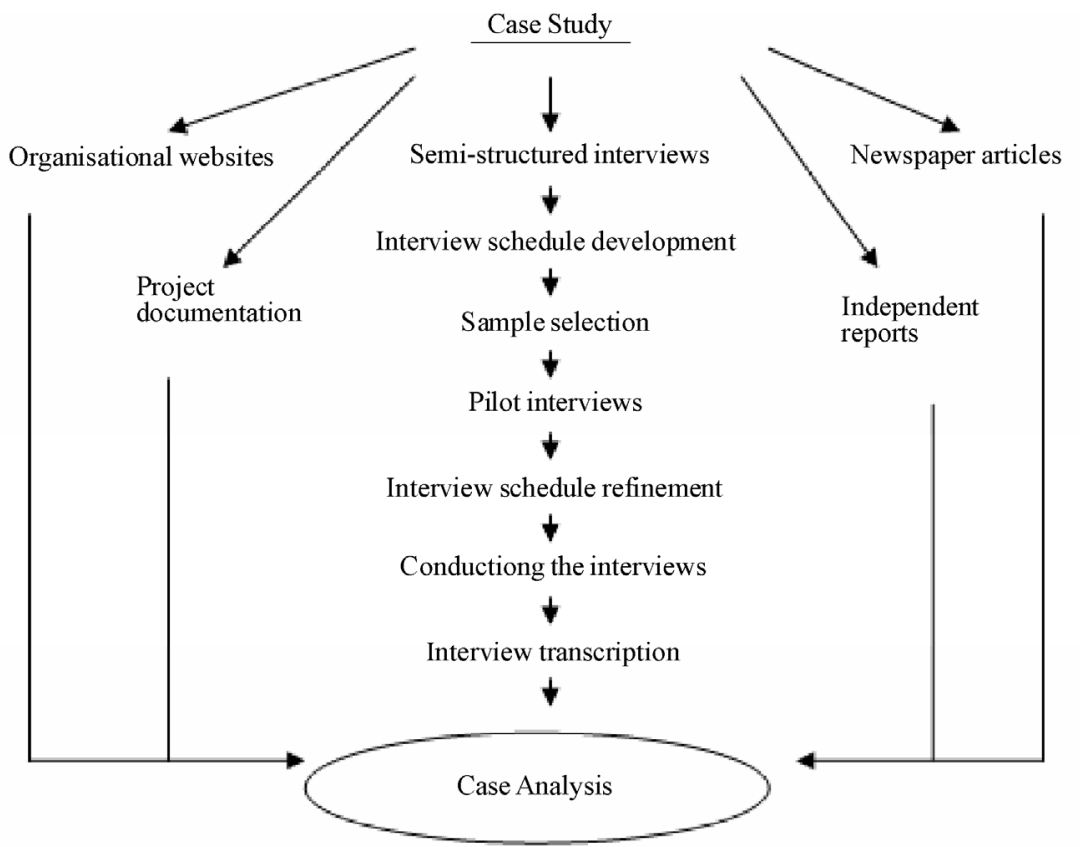

Figure 2. Research methodology

Case studies were conducted within five IoTs. Purposive sampling was used in case site selection as this sampling strategy ensures that key research themes are addressed and that diversity in each category is explored. The five case sites were selected due to their diversity in a number of respects. They participated in different implementation waves, were geographically dispersed and differed in their student population sizes and academic programme offerings. The following points give a brief synopsis of the five case sites: 
- Site One was one of the first IoTs to implement the student MIS. This site had significant inhouse MIS team capabilities, who were responsible for system implementation, support and had considerable autonomy in system development.

- Site Two was a member of the first implementation wave. Due to difficulties experienced with the central change request process, its in-house MIS unit also developed additional functionality to meet end-user needs.

- Site Three was a member of the second implementation wave. This IoT was smaller than the previous two sites and had more limited technical resources.

- Site Four was the smallest IoT examined in this study and was also a member of the second implementation wave. Its project team experienced a number of personnel changes during the implementation effort.

- Site Five was a member of the final implementation wave. It experienced difficulties in resourcing a dedicated project team and its initial system start-up date was delayed. At the time of research, the system was used to a limited extent and work was ongoing in implementing core functionality.

Within those IoTs, 49 semi-structured interviews were carried out between 30 November 2005 and 24 May 2006 with senior management personnel, MIS team per- sonnel and system end users. The selected informants were closely involved in the ICT project and had in-depth knowledge of the subject area. Each interview lasted between 60 and 90 minutes, was recorded with the informants' permission and was later transcribed. The informants were given the opportunity to verify the transcripts prior to analysis. Further, the supporting documentation was valuable in corroborating the evidence collected in the semi-structured interviews. It provided a means of triangulation in that it supplied specific details, and helped to augment and substantiate the interview data. The data analysis process is outlined in Figure 3.

Data analysis was carried out using a variant of Glaser and Strauss's (1967) [22] grounded theory method. GT is one of the most widely used qualitative frameworks in business and management studies [23]. This GT analysis was supported by a Computer Aided Qualitative Data Analysis Software (CAQDAS) package called N-vivo. The $\mathrm{N}$-vivo package facilitates efficient data indexing and management, and supports analysis through for example relationship and model exploration. As outlined in Figure 3, the interview transcripts were initially imported into this software. Examination of these transcripts led to key words/ideas being identified and these were coded using N-vivo. Groupings of these codes that contain similar content are referred to as concepts in GT. As coding progressed, it became apparent that many concepts were related and these were reclassified into a se-

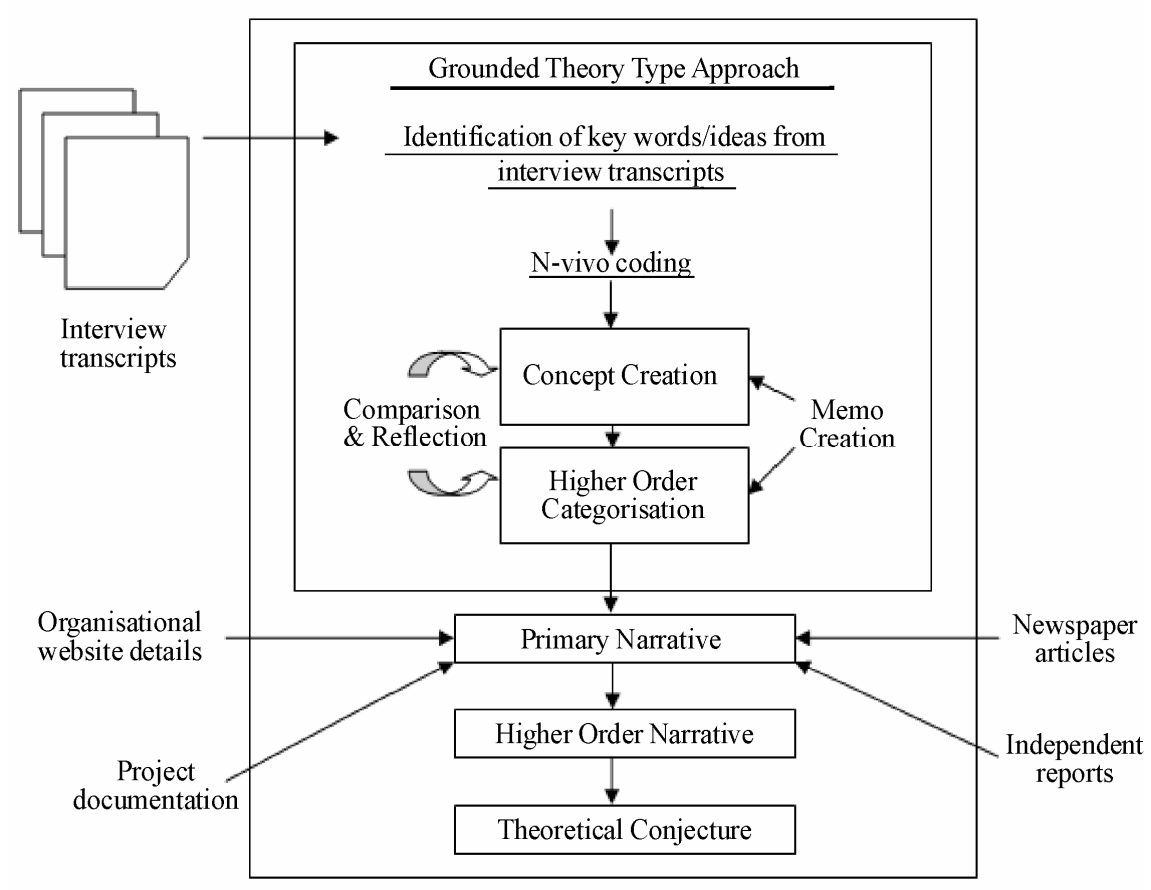

Figure 3. Qualitative data analysis 
Table 2. Degree of system exploitation

\begin{tabular}{llllll}
\hline & & \multicolumn{2}{c}{ IoT’s Degree of System Exploitation } & \\
\hline System Capabilities & Site One & Site Two & Site Three & Site Four & Site Five \\
Catalogue & Partly Exploited & Partly Exploited & Exploited & Partly Exploited & Exploited \\
ACS & Unexploited & Partly Exploited & Partly Exploited & Partly Exploited & Partly Exploited \\
Sections \& Blocks & Partly Exploited & Exploited & Partly Exploited & Partly Exploited & Exploited \\
CAO Interface & Exploited & Partly Exploited & Partly Exploited & Partly Exploited & (Was being implemented) \\
Admissions & Partly Exploited & Partly Exploited & Partly Exploited & Partly Exploited & Partly Exploited \\
General Person & Exploited & Exploited & Partly Exploited & Partly Exploited & Partly Exploited \\
General Student & Partly Exploited & Exploited & Partly Exploited & Partly Exploited & Partly Exploited \\
Registration & Exploited & Partly Exploited & Partly Exploited & Partly Exploited & Partly Exploited \\
Maintenance Grants & Exploited & Exploited & Exploited & Exploited & Unexploited \\
Accounts Receivable & Unexploited & Partly Exploited & Partly Exploited & Partly Exploited & Unexploited \\
Examinations & (Was being implemented) & Partly Exploited & Partly Exploited & Partly Exploited & (Was being implemented) \\
Academic History & (Was being implemented) & Exploited & Exploited & Exploited & Unexploited \\
Web for Faculty & (Was being implemented) & Unexploited & Partly Exploited & Unexploited & Unexploited \\
Letter Generation & Unexploited & Unexploited & Unexploited & Unexploited & Unexploited \\
Graduation & Unexploited & Unexploited & Unexploited & Unexploited & Unexploited \\
\hline
\end{tabular}

ries of categories (i.e. broad groups of similar content that are later used to generate theory) and related subcategories using N-vivo's hierarchical tree structure. This organised related concepts in relation to the overall research and facilitated greater understanding of the body of evidence through examining the key themes. Memo creation to clarify ideas and identify relationships between categories, constant concept comparison and iterative reflection on what was already coded were important steps in this coding process.

The key concepts and categories identified through $\mathrm{N}$-vivo coding, as well as important details from the other four sources of case study evidence were synthesised into a detailed cross-case primary narrative of the Student MIS project. Narratives play an important role in the social world; they are a form of knowledge and communication [24], as complex situations can be better understood in story format. Hence, they enable a researcher to shape various interview stories into a coherent account of the key themes. Through significant reflection on the primary narrative, it was reduced to the principal findings or themes. Reflection on the primary narrative involved considering three questions: "what does the text say?" "why does the text say what it does?", and "what is my understanding of what is taking place?". This approach was useful in providing a conceptual separation of three ways of examining the primary narrative and in expanding my interpretation over a series of stages. The processes involved in distillation of the key findings involved both creativity and flexibility. Diagrammatic representation was important in understanding the phenomenon's diversity and in exploring relation- ships and complex processes.

\section{Findings-the Issue of Functional Operational Misalignment}

Findings on several different aspects of the project were uncovered including system selection; system development for the Irish IoTs; system commissioning; ex-post performance in the early years; and ex-post performance at the time of research. These findings are discussed by Carcary (2009) [21]. This paper focuses on one of those findings i.e. the misalignment between system capabilities and IoT requirements. The main challenge facing the IoTs was the misalignment between what the system was used for at the time of research and what it was capable of delivering, and between IoT requirements and the extent to which they were met. As explained in the following sections, IoTs use of the student MIS fell short of system potential; hence, IoTs were not leveraging the system's potential advantages. Sub-optimal system usage was partly due to the system's inability to meet some IoT requirements.

\subsection{An Evaluation of System Functional Capability Exploitation}

Benefit realisation from the student MIS was sub-optimal within the IoTs. The system offered functionality for all aspects of student administration, yet many of its capabilities remained unused. For example, several informants within Site Three suggested that system usage at the time of research was "a fire fighting" exercise and was "just touching the tip of the iceberg". One end-user estimated functionality exploitation to be $35 \%-40 \%$, 
while a project team member suggested 50\%-60\%. Within Site Two, only the baseline functionality was implemented; work was ongoing in streamlining operational processes. Site Five's exploitation was limited to course set-up and registrations functionality, and significant work was required to advance the knowledge base. Site Four's system usage was equated to "scratching the surface"; estimates of exploitation ranged between 5\%$10 \%$ according to the ICT Manager and 70\%-75\% according to a project team member. Despite being the first to implement the system, Site One had according to the system's development team leader used only $10 \%$ of the baseline functionality. For example, examination-related modules were only being introduced at the time of informant interviewing. Hence, in all IoTs, informants suggested that the system was not fully exploited. Table 2 provides a synopsis of the degree of IoT's system exploitation. This suggests that certain modules were exploited, partially exploited or completely untouched.

The variances experienced in system functional capability exploitation can be linked to a number of factors:

- Implementation Wave: From Site Five's perspective, limited system exploitation was partly due to its postponed implementation deadline. However in the other case study sites, the system was stabilised between three and five years. Those IoTs had a longer timeframe to exploit the system but had not taken full advantage of this.

- Staff Knowledge and Resources: Across all IoTs, reasons for sub-optimal system exploitation were related to limited knowledge of further system capabilities and the time required to achieve system familiarity. This was linked to the scaling back of project teams and the associated training problem. Site Two explicitly cited lack of resources as key in failing to explore the system's fuller potential and implement further modules.

- Ability to Meet Requirements: The inability of some modules to meet requirements and lack of tailoring for those sites under the central structure impacted on the degree of system exploitation. The central structure had a phased approach for system development, which was restrictive for urgent IoT requirements.

\subsection{An Evaluation of the Degree of IoT Operational Requirements Met}

Across case study sites, the efficiency with which requirements were met was questionable. Many baseline modules did not meet Site One's requirements and, as stated, resulted in numerous in-house customisations and development projects. The system involved significant work for Site One's administrative staff; however in comparison to legacy applications, all informants agreed that it had substantially improved student record management. The degree of requirements met by the baseline system within Site Two was estimated by a managerial figure at $20 \%$. The functionality was too generic and deficient in reporting capabilities; hence the system was used primarily for data storage while all reporting, manipulating and controlling was done in-house. Within Site Three, the required further development of the Student MIS had not taken place. Hence, the system remained bespoke towards full-time students and was inflexible in dealing with any other applicant types. A project team member of Site Four regarded it as meeting $85 \%-90 \%$ of requirements, but suggested a complete suite of integrated products would be more beneficial. Site Five also encountered some limitations. Approximately $30 \%$ was regarded by one team member as unsuited to the Irish tertiary educational system. Table 3 outlines the degree of requirements met by the various modules; it highlights that modules either met all requirements, some requirements or were unsuited.

\subsection{Functional-Operational Misalignment}

The functional-operational misalignment uncovered impacted the extent to which administrative staff could effectively use the system. IoTs ability to address this issue depended on a number of factors:

- Site autonomy over the Student MIS: Site One had greater control over its system development. Much functionality used on a day-to-day basis was developed in-house. This was in contrast to the other case study sites that had little local autonomy. They were restricted in their ability to customise the system due to the control exercised by the central structure.

- Degree of adherence to the common national system standard versus in-house development: As stated, IoTs under the central structure's directive were tied to a common national standard. However, the central structure's development time for mission critical reports and for applications outside the full-time student population was slow and based on priority demand. Further, development was generic rather than customised to IoT specifications. Hence, all case study sites diverged to some extent from the common standard. This was primarily in developing external reporting capabilities.

- Degree of in-house development resource capability: A lack of resources was apparent in Site Two, Three and Four due to the scaling back of project teams. This impacted on:

- IoT's ability to advance the system for pro jects such as modularisation and semesterisation, and tailor it for different student co- 
Table 3. Degree of IoT requirements addressed

\begin{tabular}{|c|c|c|c|c|c|}
\hline \multirow[b]{2}{*}{ System Capabilities } & \multicolumn{5}{|c|}{ Degree of IoT Requirements Met } \\
\hline & Site One & Site Two & Site Three & Site Four & Site Five \\
\hline Catalogue & Unsuited & $\begin{array}{l}\text { Met Past Require- } \\
\text { ments }\end{array}$ & $\begin{array}{l}\text { Partly Met Re- } \\
\text { quirements }\end{array}$ & Met Requirements & $\begin{array}{l}\text { Met Require- } \\
\text { ments }\end{array}$ \\
\hline ACS & Unsuited & $\begin{array}{l}\text { Met Past Require- } \\
\text { ments }\end{array}$ & Met Requirements & $\begin{array}{l}\text { Met Past Require- } \\
\text { ments }\end{array}$ & $\begin{array}{l}\text { Met Require- } \\
\text { ments }\end{array}$ \\
\hline Sections \& Blocks & $\begin{array}{c}\text { Partly Met } \\
\text { Requirements }\end{array}$ & $\begin{array}{l}\text { Met Require- } \\
\text { ments }\end{array}$ & Met Requirements & Met Requirements & $\begin{array}{l}\text { Met Require- } \\
\text { ments }\end{array}$ \\
\hline CAO Interface & Met Requirements & Met Requirements & Met Requirements & Met Requirements & $\left(\right.$ Unknown $\left.^{2}\right)$ \\
\hline Admissions & $\begin{array}{l}\text { Met Require- } \\
\text { ments }\end{array}$ & Met Requirements & $\begin{array}{l}\text { Partly Met Re- } \\
\text { quirements }\end{array}$ & Met Requirements & $\begin{array}{l}\text { Met Require- } \\
\text { ments }\end{array}$ \\
\hline General Person & $\begin{array}{l}\text { Met Require- } \\
\text { ments }\end{array}$ & $\begin{array}{l}\text { Partly Met Re- } \\
\text { quirements }\end{array}$ & Met Requirements & $\begin{array}{l}\text { Partly Met Re- } \\
\text { quirements }\end{array}$ & $\begin{array}{l}\text { Met Require- } \\
\text { ments }\end{array}$ \\
\hline General Student & Unsuited & $\begin{array}{l}\text { Partly Met Re- } \\
\text { quirements }\end{array}$ & Met Requirements & $\begin{array}{l}\text { Partly Met Re- } \\
\text { quirements }\end{array}$ & $\begin{array}{l}\text { Met Require- } \\
\text { ments }\end{array}$ \\
\hline Registration & $\begin{array}{c}\text { Partly Met } \\
\text { Requirements }\end{array}$ & $\begin{array}{l}\text { Partly Met Re- } \\
\text { quirements }\end{array}$ & $\begin{array}{l}\text { Partly Met Re- } \\
\text { quirements }\end{array}$ & $\begin{array}{l}\text { Partly Met Re- } \\
\text { quirements }\end{array}$ & $\begin{array}{l}\text { Partly Met Re- } \\
\text { quirements }\end{array}$ \\
\hline $\begin{array}{l}\text { Maintenance } \\
\text { Grants }\end{array}$ & $\begin{array}{c}\text { Partly Met } \\
\text { Requirements }\end{array}$ & $\begin{array}{l}\text { Partly Met Re- } \\
\text { quirements }\end{array}$ & $\begin{array}{l}\text { Partly Met Re- } \\
\text { quirements }\end{array}$ & $\begin{array}{l}\text { Partly Met Re- } \\
\text { quirements }\end{array}$ & (Unknown) \\
\hline Accounts Receivable & Unsuited & Unsuited & $\begin{array}{l}\text { Partly Met Re- } \\
\text { quirements }\end{array}$ & Unsuited & Unsuited \\
\hline Examinations & $\begin{array}{l}\text { Partly Met } \\
\text { Requirements }\end{array}$ & $\begin{array}{l}\text { Partly Met Re- } \\
\text { quirements }\end{array}$ & $\begin{array}{l}\text { Partly Met Re- } \\
\text { quirements }\end{array}$ & $\begin{array}{l}\text { Partly Met Re- } \\
\text { quirements }\end{array}$ & (Unknown) \\
\hline Academic History & (Unknown) & Met Requirements & Met Requirements & Met Requirements & (Unknown) \\
\hline Web for Faculty & $\begin{array}{l}\text { Met Require- } \\
\text { ments }\end{array}$ & (Unknown) & $\begin{array}{l}\text { Partly Met Re- } \\
\text { quirements }\end{array}$ & (Unknown) & $\begin{array}{l}\text { Met Require- } \\
\text { ments }\end{array}$ \\
\hline Letter Generation & Unsuited & Unsuited & Unsuited & Unsuited & Unsuited \\
\hline Graduation & (Unknown) & Unsuited & Unsuited & Unsuited & (Unknown) \\
\hline
\end{tabular}

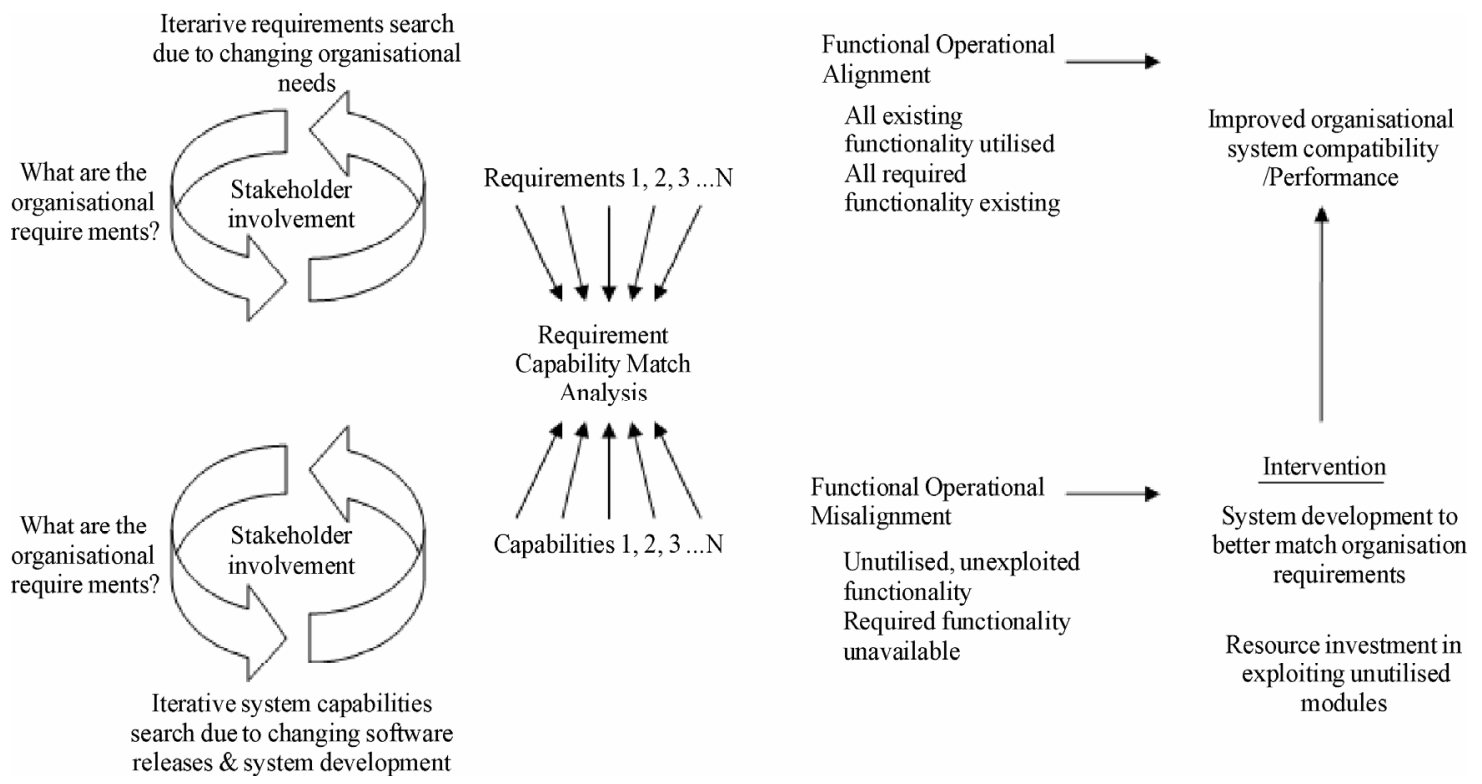

Figure 4. Addressing functional-operational misalignment

${ }^{2}$ The compatibility of a system module with IoT requirements was unknown when the module had not been exploited or examined by MIS personnel 
horts;

- $\quad$ Time lags for report development;

- The degree to which unutilised modules could be further exploited;

- $\quad$ The degree to which staff could be trained in further system capabilities and to which more efficient work practices could be found.

Those IoTs with greater resources were better positioned to address the above four points.

\subsection{Towards CPE-Addressing Functional- Operational Misalignment}

The following model provides a visual depiction of functional-operational misalignment. It puts forward a number of guidelines/steps that IoTs should consider in addressing this issue. These guidelines draw on the theoretical underpinnings of formative $\mathrm{CPE}$.

The following five steps provide an explanation of Figure 4.

Step One. Organisational requirements constantly evolve. Examples of such changes in the Irish IoTs include:

- Changes in education delivery modes. These include the introduction of semesterisation, modularisation, e-learning and blended learning, and a move towards distance learning through exploiting the virtual campus concept. Each IoT had a specific timeframe for embracing these changes.

- Changes in student profiles. Examples of nonstandard students include students with subject exemptions, Socrates students, repeat students, ACCS students, Fáilte Ireland and FÁS apprentice students, adult learners and students undertaking more than one course.

Determining functional-operational alignment requires IoTs to iteratively establish what their requirements are.

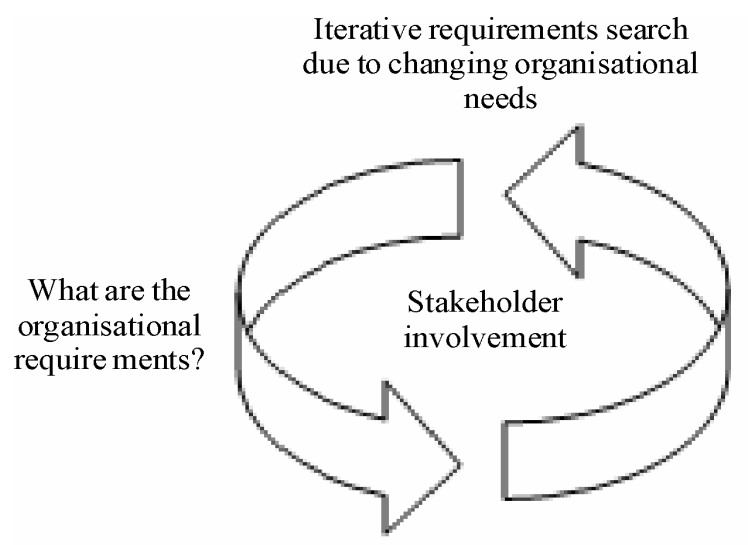

Figure 5. Determining organisational requirements
This process is outlined in Figure 5. Key stakeholder groups need to be involved. In the Student MIS project these stakeholders include senior management who make academic policy decisions and administrative staff who use the system.

Step Two. System capabilities also evolve. Changes to the Student MIS capabilities in the Irish IoTs are due to:

- Improvements and upgrades from the system vendor;

- Developments by the central structure or in- house MIS personnel.

Determining functional-operational alignment requires IoTs to iteratively review what the system capabilities are. This process is outlined in Figure 6. Key stakeholders need to be involved. In the Student MIS project, these stakeholders include MIS personnel who understand the system's changing functionality. Such changes also need to be promoted to administrative staff to increase their awareness of the functionality available.

Step Three. The output of the previous two steps is examined in a requirements-capability match analysis (Figure 7). It investigates the degree to which organisational-operational requirements and system functional capabilities converge. Each operational requirement is examined against relevant system components to identify how well it is supported. In totality, this exercise outlines the extent to which the system meets IoT requirements. Each system module is also examined to determine its degree of utilisation. In totality, this outlines the extent to which the IoT exploits system capabilities. This process should be documented in the format of detailed descriptions, which would better help in identifying steps for remedial action.

Step Four. The outcome of the requirements- capability match analysis (Figure 8) will be a state of functional-operational alignment and/or a state of functional-operational misalignment. Functional-operational

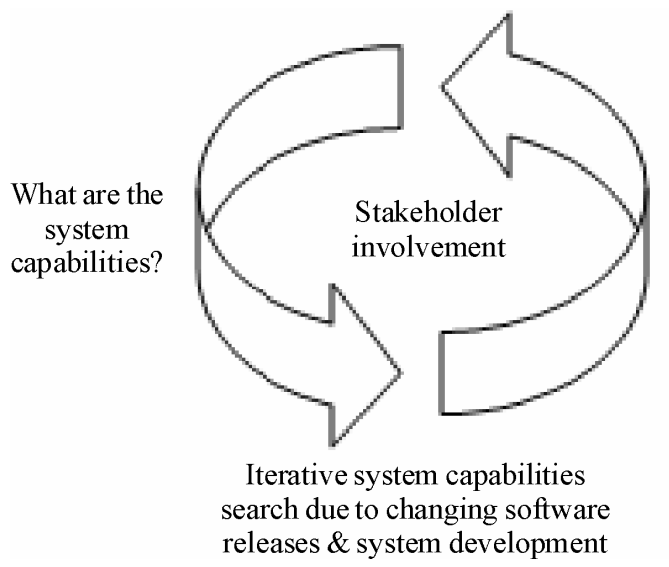

Figure 6. Determining system capabilities 

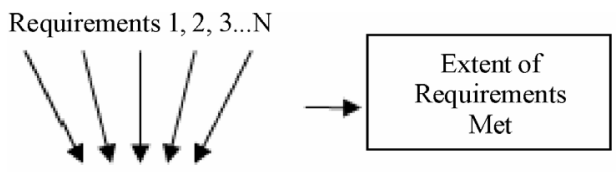

Requirement Capability Match Analysis

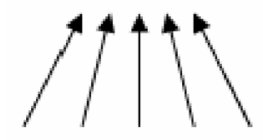

Capabilities $1,2,3 \ldots \mathrm{N}$

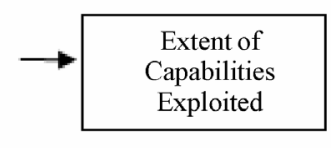

Figure 7. Requirements-capability match analysis

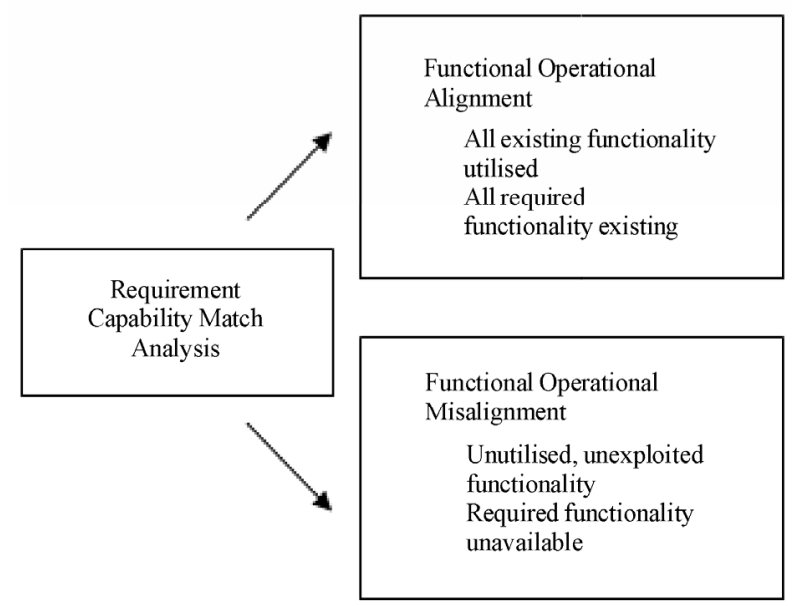

Figure 8. Functional-operational alignment or misalignment

alignment arises when all existing functionality is used and all organisational requirements are met by available functionality. Functional-operational misalignment occurs when existing functionality is unused and organisational requirements are not met by available functionality. Achieving an ideal match between requirements and capabilities is complex. The misalignment experienced across all IoT case study sites was unsurprising given the system's US orientation, the common national standard, the phased approach for system development and changing IoT requirements.

Step Five. Areas of misalignment uncovered are addressed. As outlined in Figure 9, this includes:

- System development to better match organisational requirements. This involves development by the central project team for general IoT sector needs. It also requires a degree of in-house tailoring to meet site specific demands.

- Resource investment to exploit necessary unutilised functionality. Resource investment for further system exploitation is important only where unused functionality would be of benefit to the organisation. This includes reinstating
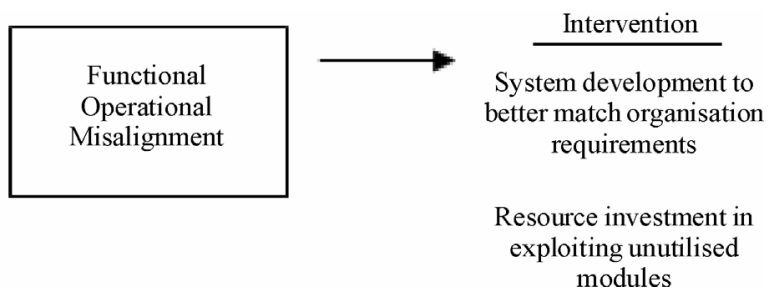

Figure 9. Addressing functional-operational misalignment

functional team members to identify unexploited capabilities and to train and educate users in the broader system functionality.

The goal of this activity is to achieve greater convergence between organisational requirements and system capabilities, with a view to improving organisationalsystem compatibility/performance and realisation of greater system benefit potential.

The above guidelines reflect in five steps how the functional-operational misalignment issue may be improved. This model may be viewed as an alternative continuous participative ICT investment evaluation tech nique that may be iteratively applied throughout the system's lifecycle. Through examining the alignment between requirements and capabilities, the IoTs can highlight problematic areas, identify steps for corrective action, set future performance targets and track progress by involving key stakeholder groups.

\section{Discussion and Conclusions}

ICT investment evaluation is important in identifying and addressing the misalignment that exists between the standard student system's functional capabilities and the diverse operational requirements of the multiple autonomous IoTs. Functional-operational misalignment results from the inability of organisations to exploit system capabilities. There is also an issue regarding whether such a system meets organisational needs. Prior to this research, the impact of functional-operational misalignment in leveraging system benefit potential was not clearly addressed in the literature. Some researchers discussed the match between system capabilities and organisational requirements. For example Avram (2001) [25] highlighted "definitional mismatch", i.e. the degree of risk faced by an organisation in terms of how well functional requirements meet operational needs; and Saastamoinen (2005) [26] suggested that the most difficult factor in ICT evaluation is the match between system and processes. However, previous research had not explored this issue in-depth or suggested how it may be addressed.

In this respect, this paper expands the body of existing research. It examined how CPE offers the opportunity to understand and exploit the unused function 
ality in a standard system through involving key stakeholder groups. This not only increases stakeholder awareness of evolving technological capabilities and organisational requirements but also promotes a more favourable acceptance to organisational changes through fostering their commitment and motivation. It can lead to enhanced stakeholder relationships through recognising the impact of organisational change and the interactions that exist between people and technology. Hence, through a continuous participative evaluation process that emphasises dialogues and stakeholder feedback, there is potential for improving functional-operational alignment and this is important for enhanced system benefit realisation.

The author's development of this CPE approach is in line with a growing volume of ICT evaluation research that recognises the value of more formative evaluation methods over rational, objective approaches that do not capture contextual depth or address important human complexities. For example, Gemmell and Pagano (2003) [7], who conducted ICT evaluation research in the Higher Education sector argued for the importance of continuous evaluation throughout the project lifecycle. Similarly, several researchers in other sectors discuss the importance of formative methods in identifying the unexpected impacts of ICT investment; monitoring progress, increasing control and improving project performance; identifying continuous improvement opportunities; improving relationships with stakeholders; and increasing benefit realisation (see for example [3-6,8-13]). As evident in the author's discussion in Section 5.4, the most important aspect in addressing the functional-operational misalignment issue is the promotion of stakeholder involvement; enabling more effective ICT decisions on how to develop the system and staff capabilities through ongoing dialogue with affected parties. This is the underlying fundamental principle of widely cited CPE methods such as Remenyi et al's (1997) [15] ABR and Cordoba's (2009) [16] IS Planning Framework. The approach developed in this paper is a further useful step in enhancing this CPE body of research in that it addresses the misalignment issue, which was not previously explored in-depth. It further adds to the limited body of evaluation research in the Higher Education Sector.

\section{Avenues of Further Research}

This study has taken a small step towards addressing the paucity of ICT evaluation research in HEIs and in providing greater understanding of the challenges in operationalising a standard ICT system in organisations with diverse requirements. However, there are many opportunities for further research in this sector.
- The research findings may be examined in a wider context. Interviews may be conducted with informants in the ten other Institutions. This would provide a basis for comparing issues across the IoT sector and for confirming or extending this study's findings. It would also determine the finding's inferential transferability to a broader setting.

- Secondly, the study's scope could be expanded to include the viewpoints of the central project team and the DoES. Due to the nature of their Student MIS project involvement; it is probable that their project perceptions differ from those directly impacted by system introduction. If this were found to be true, it would make for an interesting examination of the diversity in social groups' perceptions regarding large-scale MIS implementations.

- Thirdly, the model for resolving functionaloperational misalignment could be iteratively applied across the IoT sector. This CPE approach would provide for greater stakeholder involvement in determining evolving IoT requirements and system capabilities, and in evaluating the degree of functional-operational alignment. Further, it would focus IoT activities on problematic areas in order to improve system utilisation and benefit realisation. This project would be longitudinal; however, through setting various benchmarks, it would determine the model's usefulness in optimising ICT performance.

- Finally, the research was confined to the Irish education market. Comparative research in other countries would be of benefit. This would determine whether issues, similar to those experienced in the Irish IoTs, were encountered in implementing and operationalising large-scale standard ICT systems, and how such issues were overcome. In this respect it might be interesting to look to the UK or even the USA for comparisons.

\section{REFERENCES}

[1] M. Wilson and D. Howcroft, "Power, politics and persuasion in IS evaluation: A focus on 'relevant social groups,,” Journal of Strategic Information Systems, Vol. 14, pp. 17-43, 2005.

[2] W. Chen and R. Hirschheim, "A paradigmatic and methodological examination of information systems research from 1991 to 2001,” Information Systems Journal, Vol. 14, pp. 197-235, 2004. 
[3] S. Cronholm and G. Goldkuhl, "Strategies for information systems evaluation-six generic types," Electronic Journal of Information Systems Evaluation, Vol. 6, No. 2, pp. 65-74, 2003.

[4] C. Miskelly, A. Moggridge, C. Stephenson, and M. Williams, "Formative and interpretive approaches to the evaluation of community focused web-fronted projects," Proceedings of the $11^{\text {th }}$ European Conference on Information Technology Evaluation, Amsterdam, The Netherlands, Academic Conferences, Reading, pp. 281-288, 1112 November, 2004.

[5] A. Roudsari, E. J. Berridge, M. Vodel, and E. Carson, "Design and evaluation of ICT-based patient information systems to support the management of chronic diseases," Proceedings of the $10^{\text {th }}$ European Conference on Information Technology Evaluation, Madrid, Spain, MCIL, Reading, pp. 547-556, 25-26 September, 2003.

[6] N. Shiratuddin and M. Landoni, "Evaluation of content activities in children's educational software,” Proceedings of the $8^{\text {th }}$ European Conference on Information Technology Evaluation, Oxford, United Kingdom, MCIL, Reading, pp. 79-87, 17-18 September, 2001.

[7] M. Gemmell and R. Pagano, “A post-implementation evaluation of a student information system in the UK higher education sector,” Electronic Journal of Information Systems Evaluation, Vol. 6, No. 2, 2003.

[8] N. Doherty and L. McAulay, "The relationship between the ex ante and ex post information systems evaluation: Reflections from the literature and the practice of evaluating e-commerce investments," Proceedings of the $9^{\text {th }}$ European Conference on Information Technology Evaluation, Paris, France, MCIL, Reading, pp. 129-136, 15-16 July, 2002.

[9] E. Berghout and M. Nijland, "Full lifecycle management and the IT management paradox,” In Remenyi, D. and Brown, A. (eds.), Make or Break Issues in IT Management, Butterworth Heinemann, Oxford, pp. 77-107, 2002.

[10] N. Doherty and M. King, "The treatment of organisational issues in systems development projects: The implications for the evaluation of information technology investments," Electronic Journal of Information Systems Evaluation, Vol. 4, No. 1, 2001.

[11] B. Farbey, F. Land, and D. Targett, "Evaluating investments in IT: Findings and a framework," In Willcocks, L.P. and Lester, S. (eds.), Beyond the IT Productivity Paradox, Wiley, Chichester, pp. 183-215, 1999.

[12] B. Farbey, F. Land, and D. Targett, "Moving IS evaluation forward: Learning themes and research issues," Journal of Strategic Information Systems, Vol. 8, No. 2, pp. 189-207, 1999.

[13] Z. Irani, A. M. Sharif, and P. E. D. Love, "Linking knowledge transformation to information systems evalua- tion,” European Journal of Information Systems, Vol. 14, pp. 213-228, 2005.

[14] L. P. Willcocks, "Evaluating information technology investments: Research findings and reappraisal," Journal of Information Systems, Vol. 2, No. 3, pp. 243-268, 1992.

[15] D. Remenyi, M. Sherwood-Smith, and T. White, "Achieving maximum value from information systems," Wiley, Chichester, 1997.

[16] J. R. Cordoba, "Critical reflection in planning information systems: A contribution from critical systems thinking," Information Systems Journal, Vol. 19, No. 2, pp. 123-147, 2009.

[17] V. Serafeimidis and S. Smithson, "Information systems evaluation as an organisational institution experiences from a case study,” Information Systems Journal, Vol. 13, pp. 251-274, 2003.

[18] L. P. Willcocks, G. Fitzgerald, and M. Lacity, “To outsource IT or not? Research on economics and evaluation practice,” In Willcocks, L. P. and Lester, S. (eds.), Beyond the IT Productivity Paradox. Wiley, Chichester, pp. 293-333, 1999.

[19] C. E. Hillam and H. M. Edwards, “A case study approach to evaluation of Information Technology/Information Systems (IT/IS) investment evaluation processes within SMEs," Electronic Journal of Information Systems Evaluation, Vol. 4, No. 1, 2001.

[20] M. L. Markus, "Technochange management: Using IT to drive organisational change," Journal of Information Technology, Vol. 19, No. 1, pp. 4-20, 2004.

[21] M. Carcary, "ICT evaluation in the Irish higher education sector," Electronic Journal of Information Systems Evaluation, accepted for publication in Vol. 12, No. 2, 2009.

[22] B. G. Glaser and A. L. Strauss, "The discovery of grounded theory: Strategies for qualitative research,” Aldine De Gruyter, New York, 1967.

[23] M. Alvesson and K. Sköldberg, "Reflexive methodology-new vistas for qualitative research,” Sage Publications, London, 2000.

[24] B. Czarniawska, "Narratives in social science researchintroducing qualitative methods," Sage Publications, Thousand Oaks, London, 2004.

[25] G. Avram, "Evaluation of investments in ecommerce in the Romanian business environment," Electronic Journal of Information Systems Evaluation, Vol. 4, No. 1, 2001.

[26] H. Saastamoinen, "Exception-based approach for information systems evaluation: The method and its benefits to information systems management,” Electronic Journal of Information Systems Evaluation, Vol. 8, No. 1, pp. 51-60, 2005. 